\title{
Accuracy and Reliability of China's Energy Statistics
}

\author{
Jonathan E. SINTON* \\ Lawrence Berkeley National Laboratory \\ prepared for the China Economic Review
}

18 September 2001

\begin{abstract}
Many observers have raised doubts about the accuracy and reliability of China's energy statistics, which show an unprecedented decline in recent years, while reported economic growth has remained strong. This paper explores the internal consistency of China's energy statistics from 1990 to 2000, coverage and reporting issues, and the state of the statistical reporting system. Available information suggests that, while energy statistics were probably relatively good in the early 1990s, their quality has declined since the mid-1990s. China's energy statistics should be treated as a starting point for analysis, and explicit judgments regarding ranges of uncertainty should accompany any conclusions.
\end{abstract}

JEL Classification: C820

Key Words: China, energy statistics

* Mailing address: Jonathan E. Sinton, Lawrence Berkeley National Laboratory, 1 Cyclotron Road, MS 904000, Berkeley, CA 94720. Telephone: 510/486-7081. Fax: 510/486-6996. E-mail: jesinton@lbl.gov. 


\section{Introduction*}

China has a highly developed system of energy statistical collection and reporting. Since the early days of the People's Republic, the National Bureau of Statistics (NBS; formerly the State Statistical Bureau) has tracked output of energy products (e.g., SSB, 1986, 1989, 1992 and 1997; NBS, 1991 to 2000). In the early 1980s, NBS began publishing detailed energy consumption statistics by sector, and provincial and national energy balances. These sets of energy statistics have been long been considered the best, most comprehensive source of national-level energy data for China, and they are the starting point for statistics published by many organizations (e.g., IEA, 2000; Fridley et al., 2001; EIA, 2001; BP-Amoco, 2001).

As with other statistical indicators in China, however, changes in definitions and coverage have raised questions about reliability of trends observed over time. Problems like misreporting or non-reporting, and the difficulties in adapting the systems of data collection to rapidly changing social and economic structures have led to doubts about the accuracy of some indicators, especially economic output (Rawski, 2001; Maddison, 1997). Some sectoral and categorical definitions do not accord with accepted practices in many other countries, and contradictions between some statistics have appeared. Problems with energy statistics are not confined to China, of course, and many of the same sources of confusion and inaccuracy significantly affect energy statistics from developed countries (Farla \& Blok, 2001).

Recent developments have further called China's energy statistics into question. Accelerated and disruptive changes in energy industries and the economy in the late 1990s coincided with a large, unexpected decline in energy (mainly coal) output and use that occurred even while the country reported continued strong economic growth. The apparent conflict between a growing economy and falling energy use, combined with a strong incentive to under-report coal use — in the form of a widely publicized campaign to close down small mines - have led many to conclude that either China's economic or energy statistics, and perhaps both, are incorrect. Lack of dependable data on energy use is keenly felt by those inside and outside China who make and analyze energy, economic, and environmental trends and policy.

* I am grateful to Ernst Worrell, Lynn Price, and David Fridley for reviewing a draft of this paper. This work was supported by the Assistant Secretary of Energy Efficiency and Renewable Energy of the U.S. Department of Energy under Contract No. DE-AC03-76SF00098. 
This paper briefly explores the internal consistency of energy statistics from China over the past decade (1990-2000), consistency with related statistics, coverage and reporting issues, and the state of the statistical collection and reporting system. The implications for measures of China's economic energy intensity (energy used per unit of GDP) are also discussed.

\section{Consistency}

One gauge of reliability of statistics is internal consistency and consistency with other statistical indicators. While consistency is no guarantee that statistics faithfully represent actual circumstances, the persuasive power of energy figures is increased when they accord with each other and with other indicators.

Primary energy production and use are the among most frequently reported of China's energy statistics. Typically, aggregate primary energy production and use for a given year are reported the following year in metric tons of standard coal equivalent (tce, equivalent to $29.31 \mathrm{GJ}$ or $27.78 \mathrm{MBtu}$ ). Reported primary energy output fell by $18 \%$ between 1996 and 1999, from 1,326 million tons of coal equivalent (Mtce) to 1,091 Mtce, with production flat in 2000, according to preliminary statistics (NBS, 2000 and 2001). Reported primary energy use fell less steeply, from 1,389 Mtce in 1996 to 1,301 Mtce in 1999, a drop of $6 \%$, with consumption sliding further in 2000 to 1,280 Mtce, in preliminary figures.

Figures for coal, oil, natural gas, and electricity are reported as shares of total primary energy. Output of these same energy products, plus total power generation, appear in the tables for physical output of industrial products. Energy balance tables and detailed breakouts of sectoral energy end use (at approximately the three-digit ISIC level for the industrial sector, and the two-digit level for other sectors) are published one or more years after the primary energy statistics are released. National statistics are prepared based on provincial reports that are compiled and adjusted, e.g., to account for differences in quality of coal mined and used in different places.

Unlike the energy data in the industrial product tables, the primary energy production and consumption statistics are usually revised in the year after their first appearance. Figure 1 shows the preliminary values (published in the year immediately following the reporting year) and the final values (published in subsequent years) for both primary energy production and use. For most energy categories in 
most years, the adjustments made to production statistics are far smaller than those made to consumption statistics. This is to be expected, since it is usually easier to collect information on a small number of energy producers than a larger number of energy consumers.

Table 1 shows the preliminary and final values for primary energy use. The chart and table show that (except for 1993, for reasons discussed in a later section) revisions to total energy use figures until 1996 were several times smaller than in later years. The preliminary figures for total energy use in 1997 and 1998 were revised downwards by nearly 3\%, while the preliminary 1999 figures was revised upwards by about $7 \%$. In all three years, these changes were driven by revisions to the coal consumption figures of $5 \%$ to $8 \%$, modified by upward changes to oil use of over $5 \%$ to nearly $7 \%$. While it is normal for a statistical agency to revise initial figures based on receipt of more complete information, the increasing size of the revisions suggests rising uncertainty on the part of NBS regarding its primary data sources, and a greater need to review and modify the data it receives from lower-level reporting units. This implies that the more recently published energy statistics may be subject to greater uncertainty than in earlier years.

The growing gap between primary coal output and use is of particular concern. Unlike oil, for which rising imports explain the widening between production and consumption, China's trade in coal is small compared to its total demand. Before 1999, the difference between coal production and use was generally under $50 \mathrm{Mt}^{\dagger}$, an amount easily attributable to changes in the country's stockpiles, which, at the end of 1990 amounted to nearly $200 \mathrm{Mt}$ (Wang, 1999). According to 1999 and preliminary 2000 data, however, China consumed $195 \mathrm{Mt}$ and $175 \mathrm{Mt}$ more coal in those years, respectively, than it produced, and exported a net total of $99 \mathrm{Mt}$ coal. Since the stockpiles were expected to fall to about $100 \mathrm{Mt}$ at the end of 2000 (ChinaOnline, 2000a), about the same amount as net exports, the $370 \mathrm{Mt}$ combined difference in 1999 and 2000 between output and consumption (equivalent to about 260 Mtce, or $15 \%$ of primary coal use over both years) cannot be accounted for by reported production, trade, or stock drawdowns. The most obvious candidate for the "missing supply" is unreported production, mainly from small mines, an issue taken up below. The presence of this large gap indicates that NBS has some way of counting (or estimating) coal use

\footnotetext{
${ }^{\dagger}$ In this paper, coal is converted at a rate of 0.714 tce per metric ton of raw coal, a typical conversion factor used in China.
} 
that allows it to more fully capture consumption activity than production activity - the very opposite of the typical situation.

Because eight industrial subsectors (in order, iron and steel, chemicals, building materials, petroleum refining and petrochemicals, nonferrous metals, textiles, paper, and chemical fibers) account for $44 \%$ of final energy use (1998), one would expect energy use to track output of those products. Available information on physical energy intensities (amount of energy consumed per unit of physical output) in industry and power generation indicate that they have been falling only gradually, so the correspondence should be close. This expectation is not borne out by a comparison of indexes $(1990=1)$ of output of several of the most energy-intensive products, industrial-sector GDP, primary energy use, and total electricity (Figure 2). While reported energy use fell in the late 1990s, industrial GDP and output of the products shown in Figure 2 and most other energy-intensive products (except paper and coke) continued to rise steadily. Electricity use, on the other hand, continued to rise in concert with industrial output, in line with expectations. There are a number of possible explanations for this phenomenon, e.g., rapid changes in industrial structure that transferred production to more-efficient enterprises, but all require detailed analyses of energy and economic data that have not yet been done (Sinton \& Fridley, 2000). Problems with reporting of coal use cannot be discounted.

The household sector is the largest energy consumer after industry. A variety of countervailing trends would be expected to affect household energy. China is steadily urbanizing, and ownership of major appliances is rising quickly, so one would expect to see rising energy use, particularly electricity use. Rural coal use should rise, since coal is displacing biomass fuels. In cities, many families are moving into apartment buildings, where gas stoves and central heating replace the small, inefficient coal stoves that are used for cooking and heating in traditional housing, so coal use should fall. Reported statistics show expected rapid growth in electricity use, but coal use for both urban and rural households drops off suddenly after 1996 (Figure 3). ${ }^{\ddagger}$ For urban households, this may be due in part to the long-term decline

\footnotetext{
$\$$ Statistics on household energy use include fuels and electricity used in housing that is operated by enterprises in industry and other sectors, which report separately energy used for production and that used for residential and other non-production activities.
} 
seen throughout the 1990s, but for rural households, where per capita floor areas are rising just as in cities, and use of alternative gas fuels for cooking is still miniscule, this cannot be explained. These data give the impression that electricity use is well-known, but coal use is uncertain, and probably undercounted.

\section{Coverage and Reporting Issues}

China's statistics are intended to cover all activity within its borders, but NBS has better access to information in some sectors than in others. Throughout the 1990s, the portion of economic activity within the control of government has shrunk, and with it the ability of the NBS to gather data, gradually eroding the accuracy of statistics. This is particularly true for the dominant form of commercial energy, coal. ${ }^{\S}$

China essentially has two coal markets (Horii, 2001). One is a national market, in which production is dominated by large state-owned mines that sell to large, mainly state-owned users. The other is comprised of numerous local markets, in which small, non-state mines sell to small, local customers. Statistics on production and consumption in the former market are relatively easy to collect, and probably relatively accurate. NBS does not, however, have a good grasp either of output from the tens of thousands of tiny mines operating throughout the country, nor of coal use at the many enterprises and households that use that output. In any country, well conducted and regular sample surveys are required to develop meaningful statistics on widely dispersed activities such as these. NBS has plans to conduct sample surveys that will allow it to accurately track indicators such as output from non-state mines and coal use at rural enterprises and households, but it has not done so yet (ChinaOnline, 2000b).

Collection of data on coal output from small mines has been hindered considerably by the campaign, begun in 1998 , to close small mines. The government reported that by the end of $2000,46,000$ of the 74,000 coal mines operating in 1997 had been shut down (Han, 2001; Nengyuan, 2000). Many of those mines have reopened, however, as numerous journalistic reports, including articles in the state-run Zhongguo Meitan Bao (China Coal News), have indicated, (e.g., Beech, 2001). NBS and other official

\footnotetext{
$\S$ The major form of energy that does not appear in energy statistics is biomass fuel, which includes wood, charcoal, crop wastes, and dung that is mainly used in rural households. As in other countries, survey-based estimates of biomass fuel use are prepared, but no statistical collection is attempted.
} 
sources of information either do not have or cannot report estimates of output from nominally closed mines, so it is very likely that even the revised coal production statistics in 1998 and later years substantially undercount actual coal output. If one assumes that half of the closed mines reopened and engaged in fullscale production, and that each produced the 8,000 tons per year typical of small non-state mines (Horii, 2001), then they would produce 183 Mt per year of coal (or 130 Mtce) — approximately the gap calculated above between official figures for primary coal output and use. This is a merely hypothetical calculation, but it demonstrates that NBS may already be accounting for China's "missing supply" in its statistics on coal consumption.

For some end-use sectors dominated by a few, large state-owned entities, like the iron and steel industry, reliable statistics on consumption are available. In some other sectors, however, there is only a thin statistical basis for gathering energy use statistics, especially those in which non-state enterprises are more numerous. Because NBS has better access to information from state-owned units, as the non-state share of economic activity has risen, energy statistics have become less accurate. For example, coal consumption at China's several dozen largest, mainly state-owned cement plants is very well characterized, but coal use by the thousands of non-state plants that produce most of China's cement, on the other hand, is not known with any certainty, and can only be estimated from what is known about typical energy performance of those plants and output statistics (Sinton, 1996).

Statistics on oil production and use are much better characterized than for coal. On the production side, the three major oil companies produce virtually all of China's crude, and a few dozen refineries produce over $90 \%$ of China's oil products. More questions have been raised about consumption statistics. The sectoral breakdown is questionable, because a great deal of transport fuel use is reported in nontransport sectors, since industrial and agricultural enterprises, as well as individuals operate a large fraction of China's motor vehicles, and their consumption of motor fuels is reported as industrial, agricultural, or household consumption. The corrections needed to reallocate all motor vehicle fuel use to the transport sector, to accord with international practice, are relatively easy to estimate. Of greater concern has been the impact of smuggled oil products. The volume smuggled is thought to have peaked in 1998, at a volume of 8 to $12 \mathrm{Mt}$ (4\% to $6 \%$ of reported total oil use; Sinton \& Fridley, 2000), but has since declined, particularly 
since China's dramatic rise in crude imports and refinery utilization have displaced the need for imports of oil products.

Since there is an even greater degree of government control over natural gas and electricity production and distribution, statistics should be even less prone to error than for oil. However, the magnitude of corrections to primary consumption figures for natural gas in recent years indicates that caution is still advisable, because even revisions to include or exclude natural gas sales to Hong Kong would not explain changes of the magnitude observed (Figure 1).

\section{Statistical Collection and Reporting System}

Over the past several years, reports have appeared in the Chinese and overseas press regarding false reporting and inaccuracy of statistics, and China's top leaders have for some time acknowledged the seriousness of the problem (e.g., China Daily, 1999). The problem has been particularly acute for economic statistics, as discussed elsewhere in this issue, and over-reporting of growth is rampant. This has serious consequences for analysis of economic energy intensity trends (although it may not present such a large problem for physical energy intensity trends). However, even if GDP growth has been overstated by about two percentage points per year over the past two decades (e.g., Maddison, 1997), the amount of energy consumed per unit of GDP would still have fallen steadily, as shown in Figure 4, at a rate similar to that of the U.S. and Taiwan (Sinton \& Fridley, 2000). Even if energy use were assumed not to have fallen at all after 1997, energy intensity would still have continued to fall—unless, as Rawski (2001) has argued, actual GDP growth in 1998 and 1999 was 2\% or less.

Just as for economic statistics, NBS depends on reporting from provincially controlled branches, which in turn depend on lower-level local branches in creating its national energy accounts. NBS therefore cannot independently verify energy accounts, just as for national accounts, until it is able to undertake nationwide surveys. This structural impediment can lead to situations like that experienced in 1993, when several provinces reportedly did not submit energy balances or even collect a full set of energy statistics, in part due to failure to allocate funds for collection activities. Release of statistics for that year were therefore delayed, and their quality is generally held to be lower than for other years in the early 1990 s. This is 
reflected in the large revisions made to energy statistics for 1993 compared to other years in that period (see Figure 1).

In addition to structural problems, NBS is understaffed and underfunded. Fewer than half a dozen staff in NBS are responsible for compiling national energy statistics. For comparison, the U.S. Energy Information Administration employs 375 people, although it performs many other tasks besides collecting and publishing energy data. In China, there are no regular budgetary appropriations to publish energy statistics beyond the few indicators that appear in the China Statistical Yearbook. NBS only recently obtained funding, including support from an overseas foundation, for publication of a new edition of the China Energy Statistical Yearbook, the last edition of which was issued in 1997.

\section{Conclusion}

This paper has considered some questions regarding the quality of China's energy statistics. Available information suggests that, while energy statistics were probably relatively accurate and reliable at the beginning of the 1990s, their quality has declined since the mid-1990s, and conclusions based on the most recent data should treated with care. In particular, until NBS institutes regular sample surveys of energy coal production and use, statistics on coal should be regarded as estimates. Many anomalies may never be satisfactorily explained.

This does not mean that all analysis based on China's energy statistics should be rejected. Rather, the statistics should be treated as a starting point, judgments regarding the likely range of uncertainty should be made in performing analysis, and explicit statements about reliability of the underlying data should accompany any conclusions. For instance, given what is known about the campaign to close coal mines and the inability of NBS to report production from mines that are ostensibly closed, we can conclude that the production figures for 1998 and later years are underestimates. However, an informed estimate about the magnitude of unreported coal production (and therefore consumption) suggests that the reported coal consumption figure may be close to the actual situation, and may be used in a provisional analysis. If this is true, then some of the phenomena China has exhibited, such as the long-term decline in economic energy intensity, deserve to be seriously explored. 


\section{References}

Beech, H., 2001, What dies beneath, Time Asia, 158(9), 3 September.

BP-Amoco, 2001, BP Statistical Review of World Energy 2001, www.bp.com/centres/energy/world_stat_rev, (BP-Amoco, London).

China Daily, 1999, Accurate statistics essential, 21 January.

ChinaOnline, 2000a, China to restrict coal, steel, sugar output, 2 August, www.chinaonline.com.

ChinaOnline, 2000b, National Bureau of Statistics (NBS), 22 September, www.chinaonline.com.

Energy Information Administration (EIA), 2001, International Energy Outlook 2001, Report No.

DOE/EIA-0484(2001) (Energy Information Administration, U.S. Department of Energy, Washington, D.C.).

Farla, J.C.M. \& K. Blok, 2001, The quality of energy intensity indicators for international comparison in the iron and steel industry, Energy Policy 29(2001):523-543.

Fridley, D.G., J.E. Sinton, J.I. Lewis, Zhou F.Q.. \& Li J., China Energy Databook, fifth revised edition (CD-ROM), Report no. LBL-47832 (Lawrence Berkeley National Laboratory, Berkeley; Energy Research Institute, Beijing).

Horii, N., 2001, Coal industry: development of small coal mines in market transition and its externality, in N. Horii \& Gu S.H., eds., Transformation of China's Energy Industries in Market Transition and Its Prospects (Institute of Developing Economies, Chiba) 23-62.

International Energy Agency (IEA), 2001, Energy Statistics of Non-OECD Countries 1998-1999 (IEA, Paris).

Maddison, A., 1997, Measuring Chinese economic growth and levels of performance, Joint SSB-OECD Workshop on National Accounts, Paper No. 3, 1-4 September 1997 (Paris).

National Bureau of Statistics (NBS; formerly State Statistical Bureau), 1991 to 2000, China Statistical Yearbook, 1991 to 2000 editions (China Statistics Press, Beijing). 
NBS, 2001, Zhongguo Tongji Zhaiyao 2001 [China Statistical Abstract 2001] (China Statistics Press, Beijing).

Nengyuan (Energy), 2000, Goals for the reduction in production and mine closures for the coal industry in 2000, Nengyuan 2000(3):14, March.

Han, J., 2001, Coal industry shows gains but still loses money, South China Morning Post, 6 February.

Rawski, T.G., 2001, China's GDP statistics - a case of caveat lector? (University of Pittsburgh, Pittsburgh, PA).

Sinton, J.E. \& D.G. Fridley, 2000, What goes up: recent trends in China's energy consumption, Energy Policy 28(10):671-687.

Sinton, J.E., 1996. Energy Efficiency in Chinese Industry: Positive and Negative Influences of Economic System Reforms, Ph.D. dissertation (Energy and Resources Group, University of California, Berkeley).

State Statistical Bureau (SSB; now NBS), 1986, 1989, 1992, \& 1997, China Energy Statistical Yearbook, 1986, 1989, 1991, \& 1991-1996 editions (China Statistics Press, Beijing).

Wang Duanwu (1999a) 1999 nian meitan shichang gongxu xingshi yuce [Forecast of coal supply and demand in 1999], in: State Power Corporation, Zhongguo Dianli Shichang Fenxi yu Yanjiu 1999 [Analysis and Research on China's Electricity Market 1999] (State Power Publishing House, Beijing) 99-104. 


\begin{tabular}{|c|c|c|c|c|c|c|c|c|c|}
\hline & \multicolumn{2}{|c|}{ Total Primary Energy } & \multicolumn{2}{|r|}{ Coal } & \multicolumn{4}{|c|}{ Oil } & \multirow[b]{2}{*}{ Adjustment } \\
\hline & $\begin{array}{l}\text { Preliminary } \\
\text { Value }\end{array}$ & $\begin{array}{c}\text { Final } \\
\text { Value }\end{array}$ & Adjustment & $\begin{array}{l}\text { Preliminary } \\
\text { Value }\end{array}$ & $\begin{array}{l}\text { Final } \\
\text { Value }\end{array}$ & Adjustment & $\begin{array}{c}\text { Preliminary } \\
\text { Value }\end{array}$ & $\begin{array}{l}\text { Final } \\
\text { Value }\end{array}$ & \\
\hline 1990 & 980.00 & 987.03 & $0.7 \%$ & 740.88 & 752.12 & $1.5 \%$ & 166.60 & 163.85 & $-1.7 \%$ \\
\hline 1991 & $1,023.00$ & $1,037.83$ & $1.4 \%$ & 777.48 & 789.79 & $1.6 \%$ & 173.91 & 177.47 & $2.0 \%$ \\
\hline 1992 & $1,089.00$ & $1,091.70$ & $0.2 \%$ & 815.66 & 826.42 & $1.3 \%$ & 196.02 & 191.05 & $-2.5 \%$ \\
\hline 1993 & $1,117.68$ & $1,159.93$ & $3.8 \%$ & 813.67 & 866.47 & $6.5 \%$ & 219.07 & 211.11 & $-3.6 \%$ \\
\hline 1994 & $1,227.37$ & $1,227.37$ & $0.0 \%$ & 920.53 & 920.53 & $0.0 \%$ & 213.56 & 213.56 & $0.0 \%$ \\
\hline 1995 & $1,290.00$ & $1,311.76$ & $1.7 \%$ & 967.50 & 978.57 & $1.1 \%$ & 223.17 & 229.56 & $2.9 \%$ \\
\hline 1996 & $1,388.11$ & $1,389.48$ & $0.1 \%$ & $1,041.08$ & $1,037.94$ & $-0.3 \%$ & 242.92 & 250.11 & $3.0 \%$ \\
\hline 1997 & $1,420.00$ & $1,381.73$ & $-2.7 \%$ & $1,043.70$ & 987.94 & $-5.3 \%$ & 264.12 & 281.87 & $6.7 \%$ \\
\hline 1998 & $1,360.00$ & $1,322.14$ & $-2.8 \%$ & 973.76 & 920.21 & $-5.5 \%$ & 269.28 & 284.26 & $5.6 \%$ \\
\hline 1999 & $1,220.00$ & $1,301.19$ & $6.7 \%$ & 818.62 & 884.81 & $8.1 \%$ & 285.48 & 301.88 & $5.7 \%$ \\
\hline \multirow[t]{3}{*}{2000} & $1,280.00$ & & & 857.60 & & & 302.08 & & \\
\hline & Natural Gas & & & Hydroelectri & & & & & \\
\hline & $\begin{array}{c}\text { Preliminary } \\
\text { Value }\end{array}$ & $\begin{array}{l}\text { Final } \\
\text { Value }\end{array}$ & Adjustment & $\begin{array}{l}\text { Preliminary } \\
\text { Value }\end{array}$ & $\begin{array}{l}\text { Final } \\
\text { Value }\end{array}$ & Adjustment & & & \\
\hline 1990 & 20.58 & 20.73 & $0.7 \%$ & 51.94 & 50.34 & $-3.1 \%$ & & & \\
\hline 1991 & 20.46 & 20.76 & $1.4 \%$ & 51.15 & 49.82 & $-2.6 \%$ & & & \\
\hline 1992 & 21.78 & 20.74 & $-4.8 \%$ & 55.54 & 53.49 & $-3.7 \%$ & & & \\
\hline 1993 & 22.35 & 22.04 & $-1.4 \%$ & 62.59 & 60.32 & $-3.6 \%$ & & & \\
\hline 1994 & 23.32 & 23.32 & $0.0 \%$ & 69.96 & 69.96 & $0.0 \%$ & & & \\
\hline 1995 & 23.22 & 23.61 & $1.7 \%$ & 76.11 & 80.02 & $5.1 \%$ & & & \\
\hline 1996 & 22.21 & 25.01 & $12.6 \%$ & 81.90 & 76.42 & $-6.7 \%$ & & & \\
\hline 1997 & 31.24 & 23.49 & $-24.8 \%$ & 80.94 & 85.67 & $5.8 \%$ & & & \\
\hline 1998 & 28.56 & 29.09 & $1.8 \%$ & 88.40 & 88.58 & $0.2 \%$ & & & \\
\hline 1999 & 34.16 & 28.63 & $-16.2 \%$ & 81.74 & 85.88 & $5.1 \%$ & & & \\
\hline 2000 & 32.00 & & & 88.32 & & & & & \\
\hline
\end{tabular}

Table 1. Primary energy consumption in China by energy source, million metric tons of standard coal equivalent. Preliminary statistics are those that appear the first time data for a given year are published in the China Statistical Yearbook (CSY). Final values are those that appear in subsequent editions of the CSY. Values for 2000 are from the China Statistical Abstract, 2001.

Source: NBS (SSB), 1991-2001. 

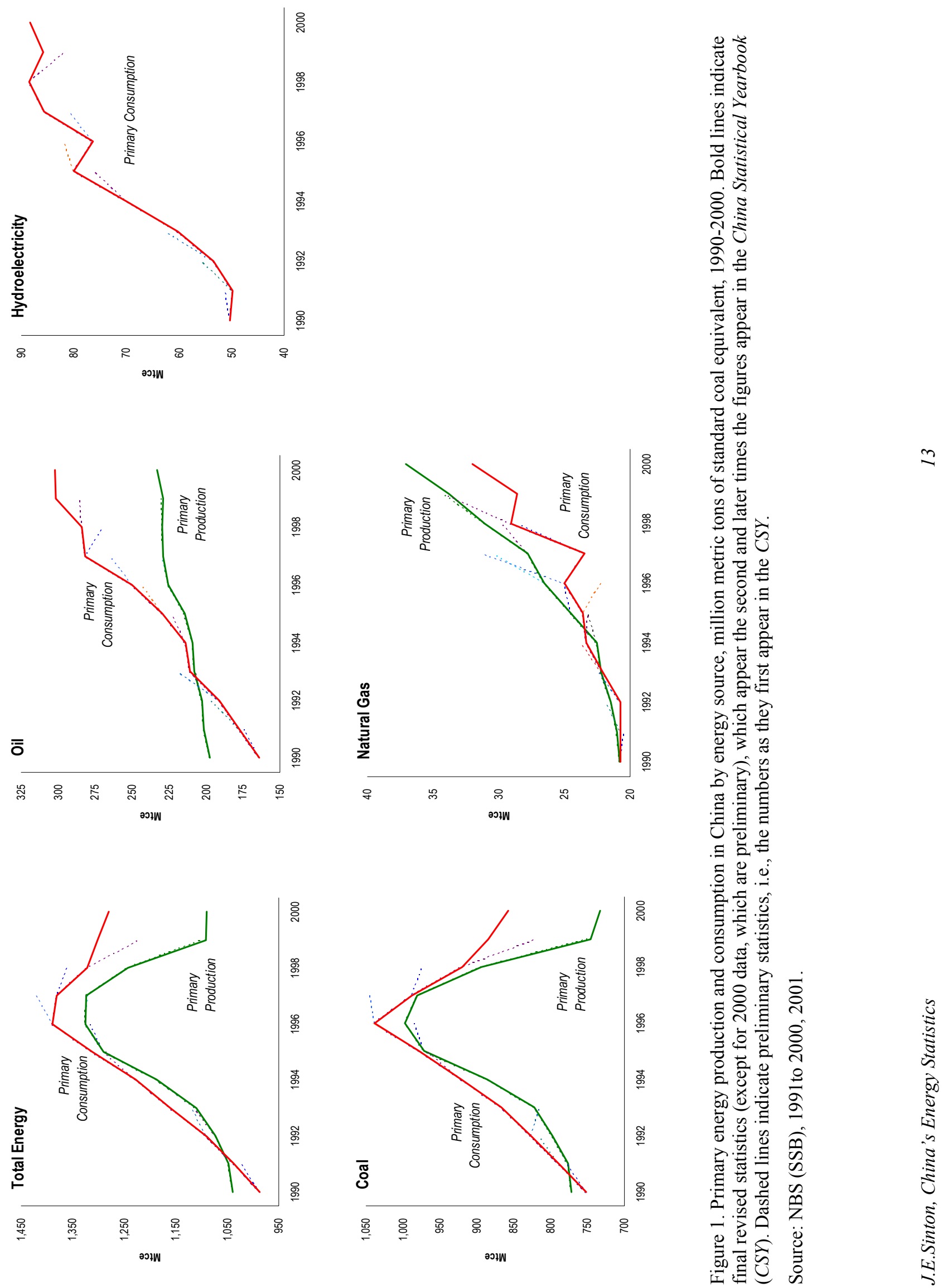


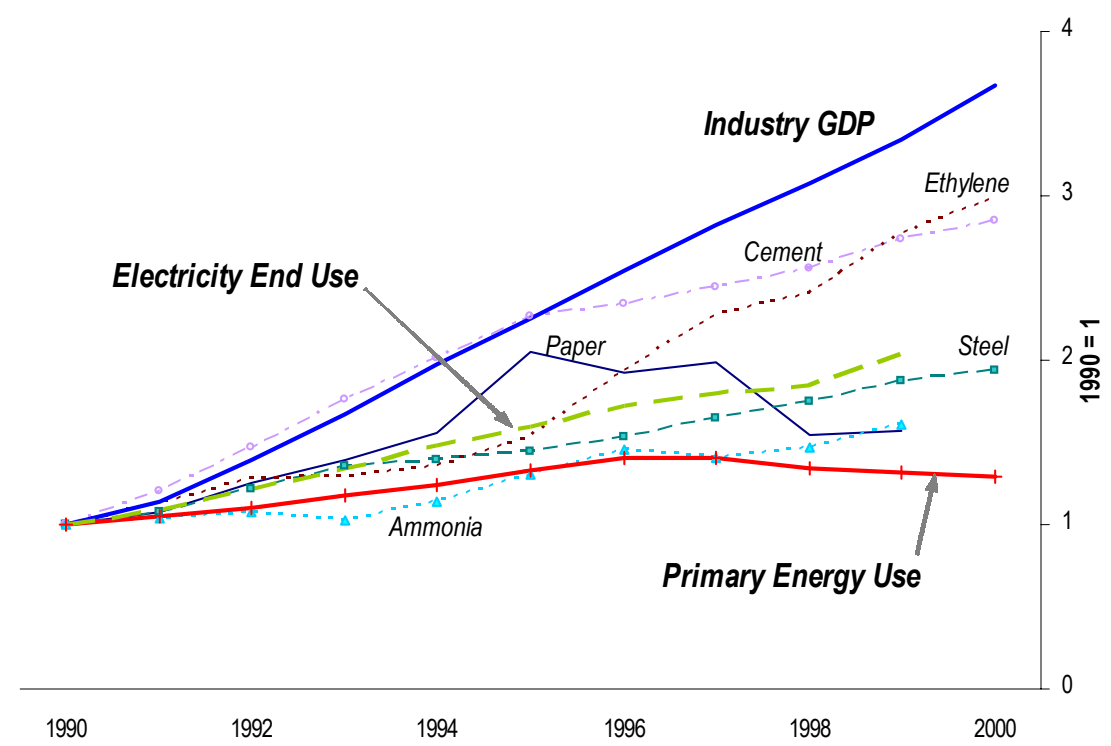

Figure 2. Indexes of energy use, industrial-sector GDP, and output of major energy-intensive products, 1990-2000.

Source: NBS, 2001. 

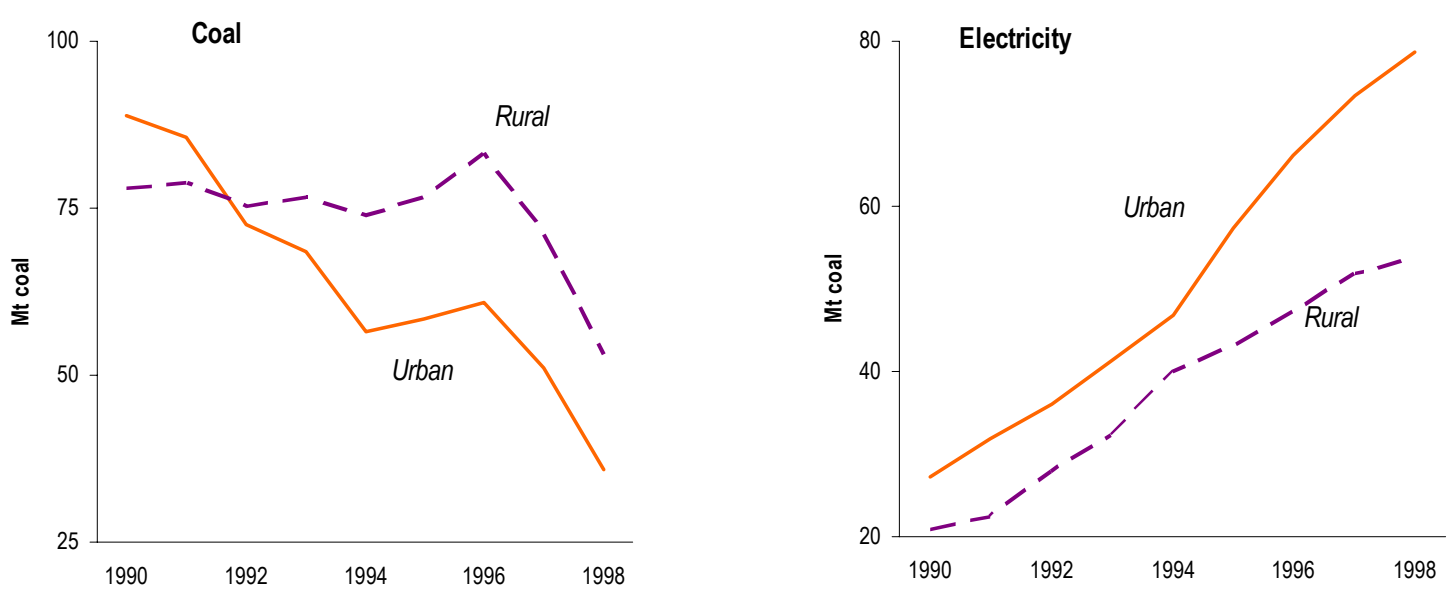

Figure 3. Reported coal and electricity consumption by urban and rural households, 1990-1998.

Source: Fridley et al., 2001; NBS, 1999 and 2000. 

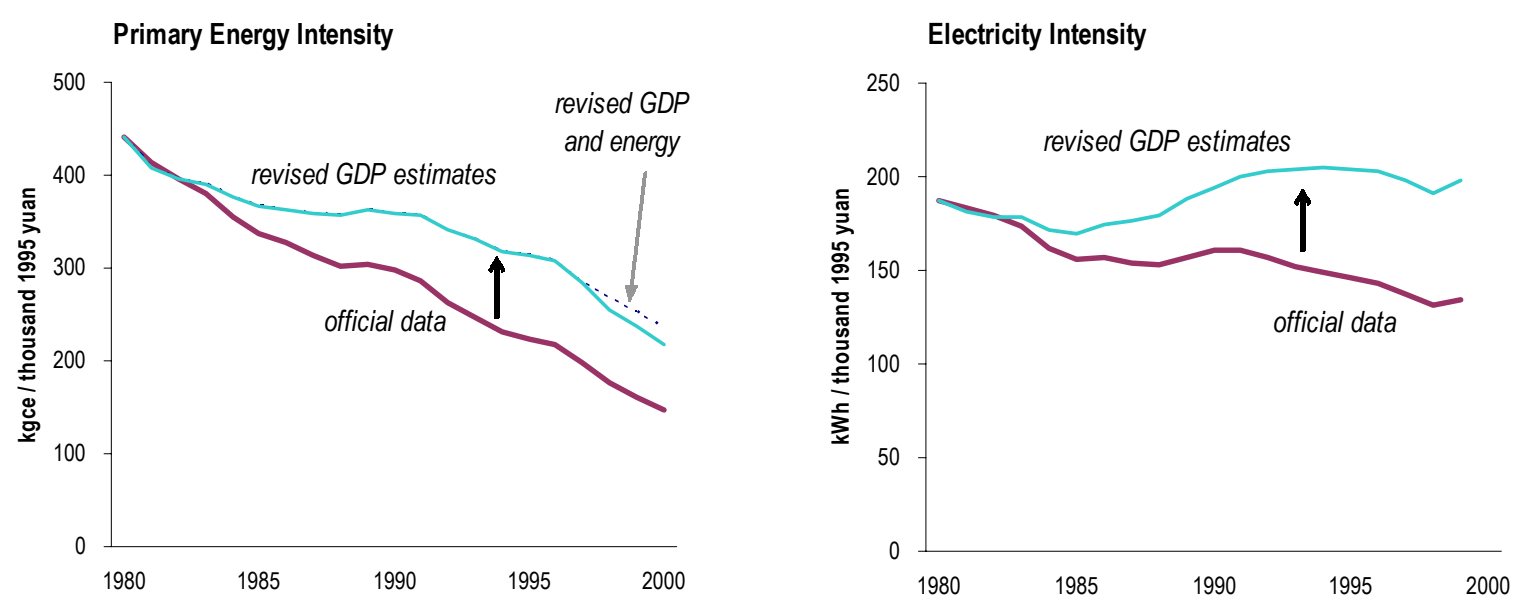

Figure 4. Primary energy and electricity intensities of GDP, kilograms of coal equivalent and kWh per thousand 1995 yuan, 1980-2000. Statistics for 2000 are preliminary. The lower line in both charts is calculated using official data. The upper line is calculated assuming that actual GDP growth is approximately two percentage points lower than official data from 1980 to 2000 . The dashed line in the chart on the left is calculated by further assuming that primary energy use is constant from 1997 to 2000.

Source: NBS, 2001; Sinton \& Fridley, 2000. 